\title{
¿Un Cristianismo postreligional?
}

\author{
A postreligional Christianity? \\ Um cristianismo postreligional?
}

Pierre Simon Arnold Gulikers*

\begin{abstract}
Resumen
Parto de la hipótesis que el Cristianismo fundacional no es una religión sino un humanismo suprareligioso. Sustento esta afirmación al someter diferentes dimensiones del movimiento cristiano primitivo a une hermenéutica postreligional. Considero que lo que llamo la Cristiandad es una deriva religiosa institucional del Cristianismo, iniciada con el Edicto de Milán y preparado desde antes a partir de las Cartas Pastorales. En esta perspectiva, la crisis actual del sistema religioso de Cristiandad es una oportunidad para retornar a los orígenes de un Cristianismo supra e interreligioso. Finalmente propongo de considerar el Cristianismo contemporáneo, por ser intimamente ligado a la aventura cultural histórica del Occidente, como el movimiento espiritual mejor preparado para abordar el giro postreligional y para proponer a otras religiones, menos acostumbradas a la crítica y autocrítica occidental que el Cristianismo, una nueva ubicación de lo religioso en contexto de postmodernidad.
\end{abstract}

Palabras-clave: religión; diálogo inter-religioso; cristianismo; cristiandad.

\begin{abstract}
I assume that the foundational Christianity is not a religion but a sort of suprareligious humanism. I support this statement by submitting different dimensions of the primitive Christianity to a postreligional hermeneutics. I consider that what we call Christianity is a deviation of the religious institutional Christianity that started with the Edict of Milan, but that was prepared earlier from the Pastoral Letters. In this perspective, the current crisis of the religious system of Christianity emerges as an opportunity of returning to the origins of a supra and interreligious Christianity. Finally, I propose to consider contemporary Christianity, for it is closely linked to the historical adventure of the West, as the best prepared spiritual movement to deal with the postreligional spin and also to propose to other religions that have been less accustomed to Western criticism and self-criticism than Christianity a new space to the religious phenomenon in the context of modernity.
\end{abstract}

Keywords: religion; inter-religious dialogue; Christianity.

\section{Resumo}

Parto do pressuposto de que o cristianismo fundacional não é uma religião, mas um humanismo suprareligioso. Fundamento esta afirmação ao submeter diferentes dimensões do movimento cristão primitivo a uma hermenêutica postreligional. Considero que o que chamamos de cristandade é um desvio religioso institucional do cristianismo que começou com o Edito de Milão, mas que foi preparado anteriormente a partir das Cartas Pastorais. Nesta perspectiva, a crise atual do sistema religioso da Cristandade é uma oportunidade de retornar às origens de um cristianismo supra e inter-religioso. Finalmente proponho considerar o cristianismo contemporâneo, por estar intimamente vinculado à aventura cultural histórica do Ocidente, como o movimento espiritual melhor preparado para lidar com o giro postreligional e propor a outras religiões, menos acostumadas que o cristianismo às críticas e autocríticas ocidentais, um novo local do religioso no contexto da pós-modernidade.

Palavras-chave: religião; diálogo inter-religioso; cristianismo; Cristandade.

Artículo recibido el 31 de julio de 2014 y aprobado el 09 de marzo de 2015.

* Doctor en Ciencias de la Comunicación, Lovaina Bélgica. Licenciado en teología, Universidad Católica, Arequipa Perú. Presidente del Instituto de Estudios de las Culturas Andinas IDECA, Puno, Peru. País de origem: Peru - E-mail: peyopeyu@hotmail.com 


\section{Introducción}

El paradigma postreligional no plantea la desaparición de las religiones, como solían hacerlo muchas profecías de la Modernidad desde el siglo XIX, sino su metamorfosis funcional radical. Esto mismo es la novedad y la originalidad de sus hipótesis de trabajo. En efecto, una simple observación histórica nos obliga a reconocer que las múltiples expresiones del fenómeno religioso, lejos de estar a la agonía, nunca han estado tan vigorosas, con sus más y menos, para bien o para mal, en nuestro contexto postmoderno. La "Muerte de Dios"” anunciada por Nietzsche es, paradójicamente, más a la orden del día que la muerte de las religiones.

La intuición postreligional nos permite desplazar el antiguo debate desde una pura confrontación bipolar entre religión y Nuevos Paradigmas, hacia un diálogo dialéctico entre los dos términos de la discusión. La pregunta ya no es la de saber si las religiones van a resistir o desaparecer bajo el embate del Cambio de Época y del movimiento de crisálida general.

Parto de la validez, a priori, de las propuestas postreligionales y de las lecturas anateistas (KEARNEY, 2010). Con este punto de partida, me parece más fecundo interrogarme sobre la capacidad relativa de las grandes religiones mundiales de emprender esta mutación copernicana.

Tal abordaje de la cuestión implica otro, en su mismo dinamismo: ¿cuáles son las condiciones históricas necesarias para que las religiones puedan, juntas o no, dar el viraje de 180 grados que exige el paradigma postreligional?

En otras palabras, mi reflexión implica dos puntos de vistas independientes e interdependientes. Por una parte, se trata que cada religión se cuestione por su

\footnotetext{
${ }^{1}$ Ver en particular todas las relecturas de las metáforas de Dios desde el cuestionamiento feminista al modelo patriarcal o de parte de los y las teólogas evolucionistas, a partir de una reformulación del concepto de creación en términos darwinianos.
} 
propia cuenta sobre la interpelación postreligional. Por otro lado (y quizás sea el reto más decisivo de cara al futuro), ¿en qué medida las grandes religiones y confesiones serán capaces de relativizar y recrear su propio discurso, su propia cosmovisión y su propia Tradición? ¿Podrán abordar mancomunadamente la nueva realidad con una voz, a la vez común y plural, en el concierto global, a lado de otras muchas voces, no necesariamente religiosas? De este doble reto depende el desplazamiento del espacio religioso en un contexto que, a priori, ya no necesita de él².

En este escenario, el presente trabajo trata el caso específico del Cristianismo de cara a estas dos preguntas. En el debate, lo cristiano goza, por hipótesis (que intentaremos confirmar en estas páginas), de dos ventajas. Primero, se trata del sistema religioso más directamente identificado y confrontado con el Occidente y, por lo tanto, históricamente más familiarizado con sus exigencias. Pero el Cristianismo es también una enorme nebulosa. Abarca tanto las expresiones más secularizadas de Europa del Norte, como modalidades orientales pre-modernas extremadamente diversas, desde Rusia o la India hasta Etiopía y Medio Oriente, pasando por el amplio abanico católico. A primera vista se trata de un extraordinario laboratorio religioso para nuestra pregunta.

\section{Una convicción de partida}

\subsection{El Cristianismo no es una religión}

En su fundamento histórico y teológico, el Cristianismo no es una religión. Si bien nació en el corazón del Judaísmo, asumiendo, en un primer tiempo, el discurso y la normatividad de su identidad judía, la religión (ritualidad,

\footnotetext{
${ }^{2}$ En efecto, la hora ya no es para la polémica o, incluso, simplemente el diálogo entre ciencia y fe, como en el pasado. Definitivamente, el Mundo postmoderno no necesita de la voz religiosa para entenderse a sí mismo. En cambio, son las religiones las que, tomando acta de la nueva cosmovisión y de la nueva antropología, están llamadas a interrogarse sobre el futuro que quieren darse a sí mismas en el concierto plural postmoderno.
} 
normatividad, discurso doctrinal, institucionalidad) no fue, sin embargo, la preocupación prioritaria de Jesús.

Por lo contrario, el anuncio de la cercanía del Reino se presenta como la superación del sistema de la religión. La sutil distinción que hacen los evangelios sinópticos entre "no abolir" y "cumplir" la Ley de Moisés constituye, de hecho, una verdadera reapropiación y recreación del discurso. La dialéctica del sermón de la Montaña se articula en la tensión conflictiva entre un "se les dijo" referido al Judaísmo contemporáneo y un “yo les digo" inaugurando una nueva etapa de la fe, la del Reino.

En la perspectiva profética, con la que Jesús se identifica a menudo en su vertiente netamente apocalíptica ${ }^{3}$, no está claro en qué medida quiso simplemente reformar y purificar el sistema religioso o, al contrario, superarlo definitivamente. Episodios fundadores, como son la confrontación con los mercaderes del templo o la parábola de la higuera, tienden a confirmar una amenaza de cancelación del sistema religioso del Templo de Jerusalén. En el capítulo cuatro de San Juan, dialogando con la samaritana, símbolo de la herejía religiosa para el judío, Jesús proclama el fin de la ritualidad religiosa excluyente (el Templo o el monte Garizím) y la inauguración de su más allá místico universal que llama la adoración “en Espíritu y Verdad”.

Si adoptamos la teología lucaniana, tenemos que admitir el nacimiento y la formación religiosa del Nazareo en un ambiente judío profundamente practicante. Pero, desde este trasfondo, llama poderosamente la atención la increíble libertad religiosa de Jesús en asuntos no menores del Judaísmo, como son el sábado, las normas de pureza, las estructuras patriarcales, la riqueza etc. Indudablemente, la predicación del Reino es escandalosa para las categorías religiosas tradicionales. Este escándalo, muy seguramente, es el que llevó a la muerte en cruz. El motivo de

\footnotetext{
${ }^{3}$ Estamos cada vez más convencidos de que el profetismo de Jesús fue esencialmente apocalíptico. Su objetivo prioritario, en tal sentido, a pesar de sus consecuencias históricas evidentes, es más escatológico que directamente político o religioso.
} 
esta muerte, de parte del Mundo judío, por lo menos4, parece principalmente religioso, como lo profetiza Caifás en San Juan.

\subsection{El Cristianismo como humanismo supra-religioso}

El vuelco hermenéutico del Evangelio tiene que ver con lo antropológico: la centralidad del ser humano y su absoluta primacía en la relación con Dios. Todos sus cuestionamientos religiosos tienen que ver con el sitio del hombre y de la mujer en la Historia de la Salvación. El absoluto de la persona está por encima de la observancia del sábado. La pureza legal y religiosa es abolida al devolver a la intención del corazón su carácter exclusivo. La cancelación del privilegio patriarcal del divorcio es motivada por la reivindicación de la dignidad de la mujer.

Estos desplazamientos culminan en la gran parábola del juicio final en Mateo 25, (considerada como auténticamente de Jesús) donde la sentencia se encuentra en la relación de solidaridad con el pobre, el sediento, el enfermo, el preso. El propio Dios somete su juicio a la relación humana de fraternidad efectiva. Asimismo, a la manera de Isaías (Is 58), Mateo (Mat 5,24) invita a dejar inconcluso el sacrificio ritual para ir a reconciliarse con el hermano.

Como lo señala tanto la Carta a Diogneto como Tertuliano5, la marca distintiva de lo cristiano no se encuentra en alguna señal ritual o religiosa particular, sino en el testimonio del amor fraterno a imagen del Maestro. Jesús no instituye ningún rito específico nuevo y no propone otra ley que las Bienaventuranzas, presentadas como cumplimiento definitivo de la Tora. La eucaristía, con su trasfondo pascual judío, no es un nuevo ritual sino, como lo comenta la primera carta de Pablo a los Corintios (1Cor 11,17-33), la sacralización de la vida comunitaria entendida como cuerpo de Cristo. Para la carta a los

\footnotetext{
${ }^{4}$ Sigue vigente la discusión de los exégetas sobre el punto de vista romano en cuanto a Jesús. Parece que la preocupación religiosa judía tomó pretexto del peligro político vislumbrado por Pilato para llegar a sus fines.

${ }^{5}$ La carta a Diogneto, un texto de la antigüedad cristiana, habla de los cristianos como "el alma del Mundo", mientras Tertuliano hace del amor fraterno el signo por excelencia de su fe: "Vean como se aman".
} 
Hebreos, incluso, el nuevo sacerdocio cristiano ya no se refiere a una mediación religiosa sino al martirio del propio sumo sacerdote, Cristo, haciendo así del martirio (y no del culto) la marca distintivo de la fe.

Todos estos rasgos propios del Cristianismo primitivo nos permiten afirmar que se trata, ante todo, de una manera nueva de situar al ser humano ante Dios y ante sus semejantes. Por lo tanto, podemos atrevernos a hablar de un Humanismo de Dios, donde la religión ya no ocupa el sitio del mediador, sino que se vuelve simple expresión simbólica de una relación no mediatizada.

\subsection{La experiencia carismática e interreligiosa de la comunidad postpascual}

La dimensión supra-religiosa y el humanismo de la primera comunidad cristiana tomarán, en la etapa postpascual, rostros cada vez más diversos y plurales. En una primera etapa, inaugurada simbólicamente en Pentecostés, el Cristianismo se vuelve experiencia carismática. La novedad pentecostal consiste en comprender el Reino como acontecer, irrupción permanente del Espíritu en la multiplicidad subjetiva (cada uno escucha) y cultural (en su propio idioma) de lo humano, en contraste con la rígida uniformidad religiosa.

La intuición teológica paulina del carácter absoluto y supra-religioso ("ya no están bajo la Ley”) de la fe, explicitado especialmente en Gálatas y Romanos, da un nuevo salto cualitativo radical en la Historia del Cristianismo. Con la experiencia subjetiva de Pablo, plasmada en su enseñanza revolucionaria de la libertad del creyente, el Cristianismo postpascual se vuelve, fundamentalmente, una experiencia de corte místico.

Esta evolución postpascual del humanismo cristiano primitivo no se dará sin resistencias y conflictos religiosos internos. Una comunidad creyente, nacida en el terruño religioso judío, asume en poco tiempo dos giros copernicanos (el 
carácter carismático y místico de la Iglesia) que ponen en tela de juicio y en peligro mortal su pertenencia religiosa nativa. Encontramos ecos dramáticos de este debate y de estos conflictos en las cartas de Pablo y en los Hechos de los apóstoles. La discusión desemboca en el así llamado Concilio de Jerusalén.

En este primer gran debate universal del Cristianismo, se asienta el carácter interreligioso de la Iglesia primitiva. La identidad cristiana ya no tiene que encontrarse en una unanimidad ritual y legal (la circuncisión y la Ley mosaica) sino en la fe (rechazo de la idolatría), la coherencia ética (rechazo de la fornicación) y la solidaridad (atención a los pobres). La única condición religiosa judía, provisionalmente mantenida para todos los miembros de la Iglesia, tiene que ver con las normas alimenticias restrictivas de los conversos judíos, afín de hacer posible el signo por excelencia de lo cristiano: la comensalidad, la mesa compartida (Hechos 15 y Gálatas 2).

Al aprobar la configuración profundamente interreligiosa de la Iglesia, el Concilio de Jerusalén confirma, a su vez, la relatividad de la dimensión religiosa respecto a las nuevas categorías identitarias de lo cristiano: el humanismo creyente, el acontecer carismático y la condición mística. Estas tres columnas fundacionales del Cristianismo primitivo, sin abolir la dimensión típicamente religiosa, la somete drásticamente, sin embargo, a sus características suprareligiosas.

\subsection{La deriva religiosa de la Cristiandad}

Dos vivencias mantuvieron vigentes las utopías "supra-religiosas" del Cristianismo naciente, tal como acabamos de describirlas. La primera tiene que ver con la persecución religiosa, tanto judía como romana, y el martirio. El Apocalipsis da fe de la consolidación de la convicción primitiva a través del cuestionamiento y del testimonio martirial. Pero una segunda experiencia espiritual contribuyó poderosamente a la radicalización cristiana. Se trata de la esperanza escatológica 
fundada en la fe en la resurrección de Cristo y de la espera de la Parusía como acontecimiento contemporáneo cercano ansiosamente esperado.

Al frustrarse la esperanza escatológica de la Parusía, con la desaparición progresiva de la primera generación cristiana, la experiencia del martirio perdió, a su vez, algo de su carácter profético. En los escritos atribuidos a la segunda generación, como son las cartas Pastorales o la carta a los Hebreos, resurgen con fuerza las tentaciones religiosas, como garantes para una Iglesia amenazada y llamada a durar, contrariamente a lo esperado.

Para las Pastorales este retorno religioso se expresa en la organicidad de la Iglesia, un comienzo de clericalización jerárquica y una normatividad institucional más rígida y meticulosa. En la carta a los Hebreos, en cambio, lo que aflora es la nostalgia y el deseo confuso de volver a las seguridades y a los fastos religiosos del Templo. Si bien el autor de Hebreos fustiga estas tentaciones en nombre de la genuina esperanza cristiana primitiva, los autores de las Pastorales, en cambio, parecen querer reinterpretar la gran novedad de la libertad cristiana en categorías religiosas más estrechas. Pero el gusano de la religión, como sistema clerical, había reaparecido en el fruto recién madurado de la profecía cristiana.

La conclusión de la era martirial y la inclusión del Cristianismo en el sistema imperial romano, como su brazo ideológico, inicia la lenta pero segura deriva religiosa de lo que, en adelante, llamaremos la Cristiandad. Lo que Jesús nunca había imaginado (crear una nueva religión), lo que nos había invitado a superar por el anuncio del Reino, se vuelve realidad. La institucionalización clerical del Cristianismo se traduce en un discurso y una ritualidad nuevos y específicos, profundamente influenciados por el entorno cultural tanto helenístico como judío.

Este giro religioso parecía acabar con la novedad profética y el carácter escatológico de la Iglesia primitiva. Pero, muy pronto, un grupo de creyentes 
convencidos y protestatarios inaugura una nueva dialéctica en el seno misma de la institución clerical. Los monjes, seguidos por muchos otros y otras a través de los siglos, al reivindicar el carácter laico, carismático y místico fundacional del Cristianismo, mantienen vigente a lo largo de la Historia de la Iglesia, la afirmación profética primitiva. A través del tiempo, dicha intuición tomará formas y rostros diversos, según las circunstancias. Pero no dejará nunca de ser el aguijón en la carne de la Iglesia.

Al desentrañar, una vez más, esta veta subterránea, mística y profética, dentro de la gran crisis clerical del sistema religioso cristiano contemporáneo, podremos abordar de manera fecunda la pregunta de la postreligionalidad.

\section{Reinterpretar el primer discurso cristiano a la luz del paradigma postreligional}

Partiendo de la hipótesis expuesta en el primer apartado, me propongo argumentar mi afirmación en cuanto al germen de una experiencia postreligional presente ya en el Cristianismo primitivo. Para tal efecto, trabajaré cinco aspectos, particularmente relevantes al respecto, en la experiencia de la primera comunidad.

Primero abordaré la fe comunitaria confrontada con el reto de la cruz. Hablaré enseguida del Reino como clave hermenéutica de lo cristiano. Después, trabajaremos la simbólica eucarística como superación del culto. Estudiaremos el nuevo estatuto del sábado en Cristianismo, de cara a la religión. Finalmente, nos detendremos en el título cristológico del Hijo del Hombre como vuelco mesiánico.

\subsection{La fe comunitaria y la cruz}

Indudablemente, los primeros pasos, tanto del Nazareno como de sus discípulos, se ubican en un terruño profundamente religioso, marcado por la efervescencia mesiánica y las escatologías apocalípticas. Los evangelios de la infancia, como la articulación de la predicación de Jesús con la de Juan el Bautista, 
apuntan hacia una continuidad religiosa con el profetismo mesiánico del Primer Testamento en su último desenvolvimiento.

Pero, este anclaje en las creencias religiosas de su tiempo choca, muy pronto, con lo que Kierkegaard llama "el escándalo cristiano". Lejos de ser la simple continuación de la experiencia religiosa polifónica de Israel, el Evangelio se presenta, en particular en el discurso en la montaña de Mateo 5 y ss., a la vez como reapropiación y como ruptura para con lo anterior. Esta paradoja dialéctica se expresa en el concepto de "cumplimiento" de la Ley y en su formulación lacónica del: "Se les dijo, pero Yo les digo".

La crisis cristiana se agudiza en la medida en que se vislumbra progresivamente la exigencia de la cruz, fracaso de todas las expectativas religiosas e hito fundador de la experiencia de la fe. El escándalo evangélico coincide con una metamorfosis de las creencias hacia un verdadero desierto religioso, metamorfosis revelada en su plenitud en el Gólgota. Este proceso hacia una fe supra-religiosa es el hilo conductor del cuarto evangelio y el dilema de la confesión de fe en Cesarea en los sinópticos. De alguna manera, podemos afirmar que la fe es la crisis y el fin de la religión como sistema total de sentido.

Sin ser propiamente "arreligioso", el Evangelio denuncia proféticamente los abusos del sistema religioso e inaugura una comunidad utópica alternativa cuyas opciones, claramente anticlericales, no están centradas en el culto, la norma de la Ley o la doctrina, sino en la reforma de las relaciones a todo nivel. Eso mismo es lo que caracteriza el Reino del que trataremos más allá.

En esta perspectiva, podemos afirmar, o mejor reafirmar, con tantos otros, como Dietrich Bonhoëffer por ejemplo, que la fe, en sí, no es una experiencia propiamente religiosa. Aun cuando se vale de la simbólica religiosa para expresarse, esta no le es constitutiva ni indispensable, como se demostrará en la etapa postpascual del Cristianismo primitivo. Tal afirmación es fundamental en 
nuestra argumentación de cara al paradigma postreligional.

\subsection{La clave hermenéutica del Reino}

La polémica desatada por la paradoja de Alfred Loisy 6 , al comienzo del siglo pasado, al oponer Reino e Iglesia, está superada desde mucho tiempo. La cuestión ya no es si Jesús fundó la Iglesia o no, sino qué Iglesia fundó y, sobre todo, cuál es su relación con el Reino.

Todos están de acuerdo, hoy día, para reconocer que el Reino es el corazón y la razón de ser de la predicación del Nazareno. Su mensaje, por lo tanto, no es el anuncio de una nueva institución religiosa, sino una nueva propuesta de Mundo, de carácter escatológico, desde nuevas relaciones.

En este contexto, la Iglesia que Jesús, efectivamente, fundó, no tiene nada que ver con una religión antagónica al Judaísmo. La comunidad reunida por el Nazareno se presenta como un verdadero laboratorio, el ensayo histórico de las nuevas relaciones de Reino. La clave hermenéutica del Cristianismo no es la Iglesia sino el Reino.

Por otra parte, el "hoy" del Reino, tal como lo afirma el Jesús lucaniano en su discurso inaugural en Nazaret (Lc.4), sólo puede visualizarse y anticiparse en la práctica de una comunidad como la que forjó. No hay Iglesia sin Reino pero tampoco hay Reino sin Iglesia, como espacio-laboratorio de celebración y de acogida del Reino.

La paradoja de Loisy, sin embargo, recobra su pertinencia cuando la confrontamos con lo que llamamos el paso del "Cristianismo" a la "Cristiandad". La doble persecución religiosa de los primeros discípulos, fue, como lo hemos isto,

6 “Cristo anunciaba el Reino y es la Iglesia que vino”. (LOISY, 1907). 
una fantástica oportunidad para explicitar el hoy "supra-religioso" del Reino a través del martirio.

Pero, progresivamente, esta oportunidad se transformó en una fatalidad. Al volverse la Iglesia un nuevo sistema religioso hegemónico, con el edicto de Milán, la dialéctica Reino-Iglesia se inversó. En vez de presentarse como comunidad de Reino, llamada a reflejarlo en la práctica evangélica de una comunidad eclesial profética, la Iglesia transformó el Reino en discurso religioso.

La dimensión escatológica de la utopía cristiana, a cuyo servicio se encontraba la Iglesia primitiva, se cambió por la prioridad institucional de una religión histórica, proclamando, en su afán de perdurar, su propio mensaje dogmático alrededor del Reino. La novedad y el escándalo cristianos se volvían un simple ideal religioso y moral sin más. El tiempo del clericalismo había empezado, y para largo.

El paradigma postreligional nos llama a retornar a la primera configuración de esta dialéctica y a optar por lo que Richard Kearney llama la era "anateista”, desde donde reaprender la “vieja novedad” perdida del Reino y del Evangelio.

\subsection{Una experiencia simbólica más allá del culto: la eucaristía}

El paradigma de la tensión entre Reino y Religión se encuentra en el corazón de la eucaristía, como síntesis de la nueva utopía evangélica. Una vez más, el contexto del gesto de Jesús en la Última Cena es eminentemente religioso. Se trata de la celebración judía de la Pascua. Poco importan, en efecto, las discusiones exegéticas sobre las fechas exactas de esta celebración y la cuestión de si realmente se trataba del rito judío oficial o no. Lo que aparece claramente es la intención de los evangelistas, y, sin dudas, del propio Jesús, de enraizar la novedad cristiana en la tradición religiosa pascual de su pueblo. 
Sin embargo, como lo subraya san Lucas, al distinguir claramente dos niveles del rito (el rito antiguo y el nuevo) (Lucas 22,14-20), en la última Cena, Jesús transgrede y recrea dramáticamente toda la gesta pascual. Ya no se trata de un simple memorial ritual sino de una entrega presente y definitiva. Al poner el gesto fundador del Cristianismo en su propio cuerpo y su propia sangre, simbólicamente entregados, el Nazareno rompe con la lógica religiosa y confiere una actualidad permanente y un carácter místico-ético inédito a la mesa cristiana.

San Juan, al situar la institución en el corazón del gran discurso sobre el pan de vida en su capítulo 6, concentra aún más la atención en la dimensión histórica y antropológica de la última Cena. El lavatorio de los pies (Juan 13,1-17), acto profano por excelencia, puesto en el centro de la identidad cristiana, inaugura la sacralización cristiana de toda realidad mundana transfigurada por el amor, y, de cierta manera, acaba con el carácter hieráticamente religioso del ritual pascual judío.

No es casualidad que, al volverse culto religioso, se haya omitido este gesto, religiosamente incómodo, en el rito eucarístico de la Iglesia, reduciéndolo a una anécdota folklórica para el jueves santo.

En este sentido, la eucaristía no es, en sí, un rito religioso aislado y separado, sino el regalo de una nueva simbólica inspiradora de todas las relaciones humanas, tanto políticas como económicas, pasando por lo afectivo. Es una nueva república de amigos (Juan 15,14-17) que nos regala Jesús en un acto profundamente revolucionario. El humilde servicio pone fin a la dialéctica económico-política del maestro y del esclavo, como a la lógica religiosa patriarcal de la presidencia del padre de familia.

Al tomar la condición del esclavo, el Señor y el Maestro, cancela definitivamente toda ambición de poder competitivo o de jerarquía sagrada. Inaugura una era de reciprocidad entre iguales. Pero esta reciprocidad no es simplemente la creación de un sistema de democracia directa ideal. Adquiere un 
sentido profundamente afectivo. El conjunto de la propuesta eucarística se presenta como espacio de amistad. "No les llamo ya esclavos, sino amigos".

Y como si el Nazareo temiera que se tergiverse su intuición y se la transforme en un rito religioso más, fuera de todo compromiso ético-afectivo inmediato, añade: "háganlo ustedes". Pablo entendió perfectamente el carácter inédito y revolucionario de la mesa eucarística al decir: "cada vez que coman de este pan y beban de esta copa, anuncian la muerte del Señor hasta su regreso" (1Cor 11, 23-26). Y ante las desviaciones rituales de la comunidad de Corinto, advierte que quien no reconoce el cuerpo en la comunidad que celebra, se condena a sí mismo (1Cor 11, 27-33).

Al constatar, especialmente en el Catolicismo latino americano, que la eucaristía se ha vuelto el ritual casi exclusivo de una religión eminentemente clerical, visualizamos, entristecidos, la fatal deriva religiosa de la Cristiandad.

\subsection{El estatuto evangélico del sábado: una nueva lectura del discurso religioso}

Jesús no rompe con la Religión. La trasciende. Esta afirmación paradójica es particularmente explícita en todo lo que concierne el cumplimiento de las normas legales. Pareciera, incluso, que esta "transgresión" permanente es consciente y voluntaria de parte del Nazareno. Un jefe de sinagoga, fastidiado por las sanaciones realizadas sistemáticamente en sábado, increpa a la gente para que venga a sanarse en cualquier otro día menos el sábado. Pero, con toda evidencia, la queja se dirige al sanador mucho más que a los sanados (Lucas 13,14-17).

Esta transgresión sistemática del sábado, no sólo para sanar sino en toda circunstancia en que la humanidad está necesitándolo, no es anecdótica7. Inaugura una nueva jerarquía de valores no preestablecida por la Religión. La fórmula “el

\footnotetext{
${ }^{7}$ Ehrman (2014) afirma que el nazareno no transgrede nunca la Ley en sí sino sus interpretaciones fariseas.
} 
sábado ha sido creado para los humanos y no los humanos para el sábado” pone el humanismo cristiano como nueva referencia absoluta por encima de todo principio religioso.

Del mismo modo, la meticulosidad con la que la ley prevé los casos de impureza y su recuperación ritual se ve barrida por una burla casi vulgar. Reduce la importancia de lo que entra en el cuerpo a un problema de digestión (Mateo 15,11 y siguientes). Sin suprimir explícitamente el discurso, la transgresión evangélica lo voltea hasta quitarle toda otra legitimidad que el servicio de la Vida.

\subsection{La nueva significación del título "Hijo del Hombre"}

Podemos resumir todo el proceso de metamorfosis religiosa del Evangelio por una única prioridad de parte de Jesús: el ser humano en todas sus variantes, especialmente las más vulneradas. Es lo que hemos afirmado ya en nuestra primera parte al hablar del "Humanismo de Dios".

Pero, al escoger para sí mismo el enigmático título de "Hijo del Humano"8, Jesús nos incita a hacer un paso más en la desarticulación del discurso religioso. No se trata sólo de cuestionar la mediación religiosa entre Dios y los humanos, sino de proponer una nueva e inédita metáfora del Dios humanado.

Al pedido de Felipe de enseñarles el Padre (Juan 14,8-9), Jesús no deja dudas: en adelante sólo su Humanidad entregada será la verdadera y definitiva imagen de Dios. La encarnación no es, por lo tanto, un simple episodio de la teodicea cristiana. Es su raíz, su fuente y su esperanza definitivas. No se trata sólo del Humanismo de Dios sino de la Humanidad de Dios como lugar definitivo de adoración y de culto “en Espíritu y Verdad”, como dice Jesús a la Samaritana en Juan 4 .

\footnotetext{
${ }^{8}$ En su polémico y convincente estudio ya aludido más arriba, Bart D. Ehrman afirma que, cuando habla del Hijo del Hombre, el Jesús histórico no se identifica con él, sino que lo considera como distinto de sí mismo. Sin embargo, en la mente de los evangelis tas y de la Iglesia primitiva, podemos considerar que esta identificación sí está realizada y que es parte de la convicción teológica cristiana posterior. Nos referimos a esta dimensión cristológica de este título en nuestra argumentación.
} 
Elizabeth E. Johnson en su libro Ask the Beasts (2014), refiriéndose a la afirmación de Karl Rahner sobre la centralidad de la encarnación, arriesga una novedosa visión de la encarnación que llama "Deep incarnation". Constatando que el prólogo de Juan no habla de encarnación en la Humanidad, ni menos en la "masculinidad", sino, más ampliamente, en la "carne", propone comprender todo el proceso de la redención desde allí, incorporando en esta visión el cosmos entero. El Emmanuel, en este sentido, no sería solamente el que "viene" a morar entre nosotros, sino aquella revelación universal de lo divino.

Esta Humanidad Cósmica de Dios Emmanuel en la carne, además, no se encuentra simplemente en el recuerdo de la Humanidad de Jesús. Estamos llamados a encontrarla en directo y permanentemente en el hermano, la hermana humanos, especialmente en el sufriente y la víctima (Mateo 25,3-46), y más allá, como lo dirá san Pablo, en el "gemido de la creación entera"(Romanos 8,18-20). En esta nueva imagen de Dios, tanto el que da el vaso de agua como aquel que lo recibe se vuelve revelación en la relación de humana compasión.

En el contexto de efervescencia mesiánica en el que vivía Jesús, el título de Hijo del Hombre se refiere también a la enigmática figura del profeta Daniel que reencontraremos en el Apocalipsis (Daniel 10 y Apocalipsis 1,9-20). Esta segunda interpretación, lejos de desmentir la primera, más directamente antropológica, la transfigura en una portentosa figura de Humanidad en proceso de deificación, como lo dicen los ortodoxos. Es como si la Humanidad Crística invadiera progresivamente toda realidad, a la vez cósmica e histórica (en particular con la simbólica de la Jerusalén celestial y mesiánica).

Con esta última revelación de una Humanidad trascendida, culmina la desarticulación cristiana del discurso religioso, desde donde podremos abordar el debate postreligional que nos ocupa. 


\section{El Cristianismo postpascual reinterpretado a la luz del paradigma postreligional}

Es en Antioquía que nació el "Cristianismo" como movimiento específico distinto del Judaísmo (Hechos 11,26). Esta metrópolis helenística fue el semillero de una nueva generación entre los cuales, probablemente, se encontraba Lucas, el evangelista. Fue tierra de inspiración de Pablo y el nuevo punto de partida de la misión hacia los gentiles.

El carácter suprareligioso de la comunidad de Jesús iba a entrar así en una nueva etapa, por la presión y la experiencia comunitaria del Mundo griego. Con la intuición paulina de la fe por encima de la Ley, el Humanismo Cristiano se presenta, en adelante, como un espacio plural, tanto a nivel de las expresiones religiosas como del discurso filosófico y teológico.

El Cristianismo echa raíces en la nueva cultura helenística dominante y, con asombrosa libertad y adaptabilidad, logra expresarse como alternativa de la esperanza sin una mediación religiosa exclusiva. En este sentido, se trata de un fenómeno transcultural y trans-religioso único en la Historia de los movimientos espirituales. Pablo, algo enfadado e impaciente, intenta explicar a los paganos Gálatas, tentados de judaizar, que esta nueva libertad universal es esencial a la fe.

El Judaísmo, por cierto, al calor del Exilio, había conocido ya una corriente universalista admirable y abierto espacio para los gentiles convertidos o simpatizantes. Sin embargo, a pesar de la helenización masiva de la diáspora judía, la propuesta para los no judíos no pasaba de una discreta adaptación (ver el Sirácides) y de una invitación a acercarse progresivamente de una religión judía referencial.

El Cristianismo, al contrario, es una verdadera recreación original de un discurso que intenta hacer dialogar los dos Mundos, precisamente porque su 
fundamento universalista se sitúa más allá de toda referencia religiosa y cultural particular.

\subsection{Reino y cosmovisiones}

Una de las objeciones mayores de los creadores del paradigma postreligional al discurso religioso pre-moderno es su carácter agrario y neolítico arcaico. Indudablemente, el trasfondo mitológico de la Biblia y del inconsciente religioso semítico está repleto de estas referencias. No se puede negar tampoco su persistencia en el inconsciente colectivo cristiano hasta hoy.

Sin embargo, el Cristianismo nacido en contexto helenístico es esencialmente urbano. Toda la misión de Pablo se desenvuelve entre ciudades importantes del imperio. La segunda generación de creyentes es netamente urbana y de ciudades helenísticas cultural, religiosa, comercial y políticamente de primer orden.

En este sentido, los debates éticos y místicos de la comunidad postpascual tienen que ver con cuestiones propias de la ciudad. Por cierto no se puede comparar el Mundo antiguo con nuestra sociedad urbanizada. Las referencias hermenéuticas siguen siendo, evidentemente, las de un mundo pre-científico, neolítico Sin embargo, en el Nuevo Testamento postpascual, la dimensión mitológica agraria del discurso religioso tradicional es minoritaria. Los desafíos se sitúan en el plan filosófico (cuestión del pre-gnosticismo por ejemplo) o sociopolítico (la esclavitud, el lugar de las mujeres, los ídolos, la autoridad imperial etc.).

En esos debates, el Cristianismo aparece a la vez como hondamente inculturado (es la idea de los cristianos como "Alma del Mundo" en la carta a Diogneto) y contracultural (ver la burla del areópago de Atenas ante el anuncio de la resurrección, de parte de Pablo - Cf. Hechos 17,16-34). 
A la diferencia de las utopías mesiánicas de los profetas del Antiguo Testamento, la esperanza representada por el Reino se refiere a una simbólica netamente urbana, en particular en el Apocalipsis. La Nueva Humanidad que anuncia y prepara es una comunidad de relaciones múltiples, una red compleja de solidaridades que tienen poco que ver con el "statu quo" agrario, o las nostalgias restauradoras. El Reino es una realidad sociológica, mística y ética radicalmente nueva que mal soporta los odres viejos y los parches.

\subsection{El martirio como testimonio postreligional}

La primera experiencia del Cristianismo naciente fue el martirio. El Judaísmo, muy pronto, mató a Esteban y a Santiago y persiguió la comunidad. Asimismo, el imperio se sintió amenazado por el éxito suprareligioso de las primeras comunidades y sus contestaciones implícitas del sistema imperial.

Esta persecución se relacionó inmediatamente con la verdadera identidad cristiana. Ser discípulo o discípula de este Jesús llevaba necesariamente al martirio $^{9}$. Ser martirizados por los sistemas políticos y religiosos situaba, de entrada, la experiencia de la fe cristiana más allá de toda referencia religiosa ${ }^{10}$.

El mártir es una individualidad carismática que emerge de una convicción comunitaria en referencia al martirio de Jesús, necesariamente compartido por sus discípulos, como advierte el Evangelio. Esta nueva identidad cristiana se volvió rápidamente un ideal, una utopía colectiva, un anuncio encarnado de la locura de la cruz y de la resurrección.

La fe se comprendía como testimonio radical que dispensaba, de cierta manera, de toda pertenencia visible a una institución específica y a su discurso. En

\footnotetext{
${ }^{9}$ Tal fue también la convicción que inspiró, desde Egipto, la ruptura monástica al constatar la conclusión de la era martirial y la clericalización de la Iglesia imperial.

${ }^{10}$ Esta afirmación nuestra hace todavía más lamentable y contradictoria la reacción posterior de la Cristiandad, como religión establecida, al culpar los judíos de este martirio, empezando por la muerte de Jesús en cruz. Tal justificación del antisemitismo cristiano fue una perversión religiosa del sentido profundo y fundador de un martirio como gracia suprema de la fe.
} 
nuestro lenguaje podríamos afirmar que esta experiencia fundadora es la primera manifestación del carácter "postreligional” del Cristianismo originario.

\subsection{La utopía postreligional de la Jerusalén celestial y de su ensayo mesiánico}

La simbólica apocalíptica, tanto en Cristianismo como en Judaísmo, está enraizada totalmente en la experiencia del martirio y de la persecución. Son cada vez más numerosos los autores que abordan el mensaje de Jesús desde la perspectiva apocalíptica, y me inclino a compartir este punto de vista.

El éxito rápido de un predicador galileo, religiosa y socialmente marginal, no se explica fuera de la efervescencia mesiánica alrededor de un discurso popular sobre el fin de los tiempos. Es esencial, en este sentido, resituar la conciencia cristiana primitiva en su contexto escatológico. (EHRMAN, 2014).

Por definición, el discurso escatológico es supra religional porque anuncia una creación nueva. En la apocalíptica cristiana, que se trate de los sinópticos o del Apocalipsis de Juan, la destrucción o simplemente la obsolescencia del templo coincide con la inauguración de los nuevos tiempos, en particular en la simbólica de una futura Jerusalén sin templo. (Ap 22,22; Mat 21 y 22).

\subsection{La reivindicación carismática y los pobres}

Finalmente, quiero resaltar dos rasgos del Cristianismo postpascual esenciales en nuestra búsqueda de una fisionomía reconfigurada del Cristianismo en nuestro contexto. Estos dos aspectos me parecen estrechamente unidos: el fundamento místico-carismático de la Iglesia y la prioridad de los pobres.

Si la comunidad prepascual estuvo profundamente enraizada en el suelo religioso judío, como lo hemos señalado en nuestro apartado precedente, estamos 
intentando demostrar aquí la evolución supra e inter-religiosa de un Cristianismo inserto en una nueva cultura helenística hegemónica, urbana e imperial. En esta evolución, la experiencia mística de los principales protagonistas, especialmente Pablo, y su expresión carismática, se vuelven columna vertebral de la Iglesia.

Pasamos de un grupo religioso judío, marginal y protestatario, a un movimiento de conversos, tanto judíos como paganos, profundamente inspirados por su experiencia subjetiva e intersubjetiva.

El primer acontecimiento místico-carismático fundador del Cristianismo es, evidentemente, la resurrección. La fe del nuevo creyente se basa enteramente en el testimonio de un acontecimiento de orden místico, vivido por al menos algunos líderes del grupo, y su consecuente transformación radical que llamaremos carismática.

Los Hechos de los Apóstoles dan razón de estos acontecimientos y de su asombrosa fecundidad carismática. No por nada se suele llamarlos el Evangelio del Espíritu. El cuarto Evangelio, como testigo de la fe de la segunda generación, nos advierte que los futuros creyentes pasarán por el testimonio de los que "lo vieron". Es esta fiabilidad carismática la que permite a Pedro romper con reglas religiosas estrictas después de la visita a la casa de Cornelio (Hechos 10 y 11).

Más paradigmática aún, en este sentido, es la conclusión del concilio de Jerusalén cuya declaración final empieza con esta fórmula: "El Espíritu y nosotros", lo cual legitima la no imposición de casi todas las reglas religiosas judías para los paganos cristianos (Hechos 15, 28 y siguientes).

Pero el carácter carismático-místico del Cristianismo postpascual no se limita a la experiencia de Jesús resucitado y sus consecuencias. Indudablemente, la experiencia (ḋlas experiencias?) místicas personales de Pablo van a determinar, por una parte casi igual a la anterior, la nueva fisionomía del movimiento 
postpascual naciente. El carisma paulino, basado en su conversión, influye tan poderosamente en el contenido de nuestra fe cristiana que, a veces, nos cuesta distinguir en ella lo "paulino" de lo "nazareno".

Dicha evolución carismático-mística de la comunidad subraya el contraste con los condicionamientos institucionales que implicaría la pertenencia a una religión determinada. La libertad cristiana, que Pablo identifica con la fe, es el fruto de este carácter místico-carismático de la Iglesia en contexto helenístico.

Al dar razón de las decisiones del concilio de Jerusalén a una comunidad pagana (los Gálatas) tentada por las sirenas religiosas judías, Pablo insistirá en la centralidad del servicio al pobre como signo y consecuencia de esta nueva direccionalidad comunitaria (Gálatas 2,10). La experiencia mística de los conversos y su traducción carismática se manifiestan, prioritariamente, en la atención a los pobres, en la propia comunidad, pero también en el escenario social imperial.

Las cartas a los Corintios reflejan maravillosamente esta centralidad, lo cual explica, en buena parte, el éxito asombroso del nuevo movimiento en las capas más marginalizada de su tiempo. (Ver en particular 1 Corintios 2).

Desgraciadamente, este carácter postpascual original de la Iglesia se diluirá pronto en lo que llamaré la deriva religiosa hacia la Cristiandad. Como lo hemos visto más arriba, en las Cartas Pastorales, que por este motivo pueden difícilmente atribuirse al Apóstol, lo carismático y su justificación mística pasan a un segundo plano. Privilegian, por el contrario, la organización y las normas, tanto religiosas como morales, en un grupo en vía de institucionalización.

Esta evolución histórica inaugura, por otra parte, la nueva dialéctica en el seno de la Iglesia, entre carisma e institución, tensión que se prolonga hasta nuestros días (BOFF, 2002). La reconfiguración postreligional de la fisionomía 
eclesial pasa necesariamente por un retorno a la centralidad místico-carismática y una subordinación, a la manera del concilio de Jerusalén, del carácter institucional de la Cristiandad en crisis.

\section{La crisis de la Cristiandad contemporánea como oportunidad postreligional}

El sistema religioso de Cristiandad conoció su lento descenso en Occidente desde la revolución francesa hasta el Concilio Vaticano II. En este lapso de más de siglo y medio, los sobresaltos que sacudieron las diversas confesiones cristianas fueron numerosos, desde el movimiento liberal protestante hasta el surgimiento de corrientes religiosas nuevas, pentecostales y evangélicas. Pero sobre todo fue el escenario de poderosas reacciones de repliegue y resistencia. Si las Iglesias orientales se mantuvieron en su inmutable postura extemporánea, el Catolicismo, al contrario, adoptó una actitud defensiva más agresiva. Más allá de algunas aberturas tímidas a los cuestionamientos del tiempo (por ejemplo la encíclica Rerum Novarum de León XIII) la lógica reaccionaria quedó vigente hasta el Concilio.

\subsection{Vaticano II: ¿El canto del cisne de la Cristiandad?}

A pesar de todos sus aspectos profundamente innovadores y sin menospreciar su intento teológico, pastoral, ético y espiritual de reconciliación con la Modernidad, Vaticano II no deja de ser, sin embargo, el último discurso "total" del sistema de Cristiandad, su magnífico canto del cisne. Indudablemente, falta una segunda parte más allá de la reconciliación moderna universal. Se trata de la propia autocrítica, no sólo moral o teológica, sino histórica, del propio sistema.

Algunos reclaman un tercer Concilio. Con su carácter algo utópico e irrealizable, esta demanda, además, no va lo suficientemente lejos. El reto hoy es emprender los caminos de retorno al Cristianismo suprareligioso previo a la Cristiandad, para abordar la Postmodernidad y sus condiciones postreligionales. 
Desde el alba del tercer milenio, la Iglesia católica emitió algunas tímidas señales que podríamos llamar precursoras. Pienso, entre muchos otros gestos, en los dos encuentros de Asís convocados por Juan Pablo II. Significativos también los solemnes pedidos de perdón a la Humanidad y el consentimiento de Juan pablo II a nuevas cosmovisiones, en particular la teoría evolucionista ${ }^{11}$.

\subsection{Genero y sexualidad: punto de quiebre de la Cristiandad}

Los debates sobre la sexualidad y, más ampliamente el género, no son simplemente coyunturales. La verdadera revolución, el cambio de civilización en el que hemos entrado, afecta esencialmente la antropología, muy específicamente el lugar de la identidad, de la vivencia y de la orientación, sexuales. La nueva imagen de lo masculino y de lo femenino, de la familia, de la persona será en adelante la prueba de fuego para los discursos religiosos.

El episodio dramático inaugurado por la encíclica Humanae Vitae de Pablo VI marca, a mi parecer, el verdadero quiebre de la fortaleza de Cristiandad. Ha pasado más de medio siglo desde que estalló la crisis y sus consecuencias no acaban de sacudir la Iglesia.

Los dos próximos sínodos extraordinarios de obispos sobre la familia serán, de hecho, sínodos sobre la sexualidad, aún si no se dice públicamente. De la capacidad de emitir una palabra nueva sobre esta temática depende, en buena parte, el futuro postreligional o la muerte del discurso cristiano. Las cuestiones de los divorciados vueltos a casar, del celibato sacerdotal, de la homosexualidad, del empoderamiento de la mujer en la Iglesia etc. son todos vinculados con la sexualidad, aún si se quiere minimizar su impacto al hablar púdicamente de la "familia".

\footnotetext{
${ }^{11}$ Juan Pablo II hablando en la Academia Pontificia de Ciencias el 23 de octubre 1996: La verdad no puede contradecir la verdad. Ver en particular la afirmación de que "la teoría de la evolución es más que una hipótesis" en referencia a la postura de Pio XII, considerándola como mera "hipótesis". (JUAN PABLO II, 1996).
} 
Al tema de la sexualidad y del género se acopla la urgentísima cuestión de la relación entre pensamiento democrático e Iglesia. La crisis y las reformas de la Curia Romana anuncian, en realidad, el final de una lógica de poder absolutista, teocrático y el reclamo por la transparencia, la inter-solidaridad (la colegialidad en lenguaje eclesial). Aquí también, si somos sinceros, se trata del fin del sistema de Cristiandad en su fundamento y de una poderosa incitación a retornar a la referencia evangélica. Esta pretendida reforma es, en realidad, una agonía.

\subsection{Una revolución cosmológica y antropológica}

Estas importantes aberturas no son ingenuas ni solamente específicas. No son anécdotas de simple aggiornamiento. Inauguran, consciente o inconscientemente, una verdadera revolución epistemológica.

Dos temáticas esenciales en la doctrina cristiana se ven así confrontadas: la visión del Mundo y la visión de la vocación humana. Al considerar la teoría de la Evolución como algo más que una hipótesis, la Iglesia admite la urgencia de una reformulación radical de su teología de la creación y de su secular antropocentrismo doctrinal.

Más allá de todos los aportes valiosos de la Doctrina Social de la Iglesia sobre medio ambiente y ecología, es la metáfora de lo divino en cuanto creador y de lo humano como dueño (cfr Génesis 1) o cuidador (Génesis 2) del universo que exigen una urgente y radical revisión.

Los teólogos (y, muy especialmente hoy, las teólogas) han sido siempre los pioneros arriesgados, y muchas veces condenados, de lo que, más adelante, se considera como bien común de la Tradición cristiana. Así con el Concilio, gestado por las grandes figuras de Congar, de Lubac y otros. Asimismo con la opción preferencial por los pobres preparada por la tan combatida Teología de la Liberación y proclamada por Juan Pablo II como la opción de toda la Iglesia. 
Retomando la obra premonitoria de Pierre Teilhard de Chardin, la teología asume, una vez más, este reto de señal anticipada. Al proponernos una nueva comprensión del "acto" y del Dios creador, a la luz de las nuevas teorías del nacimiento, evolución, selección y expansión del universo y del misterio de la vida $^{12}$, ensaya admirablemente esas nuevas metáforas que necesitamos de cara a los Nuevos Paradigmas.

Sin discontinuidad con el reto cosmológico asumido por la teología evolucionista, la revolución antropológica de la teología cristiana pasa por la confrontación sincera con las teorías del género, en todas sus variantes actuales.

No es casual que estas exploraciones sean creaciones desde las mujeres y desde el Norte. La crisis de las sociedades capitalistas y del esquema patriarcal de Cristiandad revela el fracaso del modelo masculino de conquista, depredación y dominio universal. La denuncia y la propuesta alternativa no podían surgir sino de los sectores excluidos de este esquema. Como los pobres fueron los portavoces de sus propios derechos negados y los denunciadores del pecado social que los aqueja, así las mujeres asumen la misma responsabilidad en cuanto al deterioro del cosmos y la opresión sexual.

\subsection{El fracaso moral, intelectual y espiritual de los intentos recientes de Neo Cristiandad}

Pero estos intentos salen a penas de un largo y penoso ostracismo. Los años postconciliares están caracterizados a la vez por audacias, como las que acabamos de señalar, y por temores. Ante las inevitables pérdidas de espacios y poder que el anateismo postreligional en germen deja augurar, el Catolicismo de Cristiandad intentó, durante los 35 últimos años, salvarse a sí mismo como sistema global. Es lo que el papa Francisco llamó una Iglesia auto-centrada.

\footnotetext{
${ }^{12}$ Ver Elia Delio y Elizabeth Johnson.
} 
Este intento neo-conservador, lo llamaré aquí Neo Cristiandad. Fue, hasta hace poco, la propuesta hegemónica. Con un esquema de reconquista nostálgica y triunfalista, ingenuamente euro-céntrica, el Catolicismo quiso reinventar una Iglesia basada en los presupuestos de Vaticano I y de Pio XII. El resultado de esta tentativa fue catastrófico.

Fueron años dramáticos, tanto a nivel moral como intelectual y espiritual. El afán de imponer el monopolio de un discurso doctrinal preconciliar ha mantenido en la Iglesia un ambiente de sospecha, de arribismo y de caza de brujas muy poco propicio al dinamismo intelectual exigido por la coyuntura de cambio de época. No pocos mirábamos esta muerte lamentable por auto ceguera y suicidio histórico, como la frustración de una Palabra cristiana oportuna para estos tiempos.

\subsection{Una autoimagen más allá de lo confesional}

El advenimiento del papa Francisco constituye una sorpresa y un reto en muchos aspectos. Quisiera aquí detenerme en sólo dos aspectos de esta nueva manera de ejercer le primado petrino que se relacionan con nuestra problemática.

El primero tiene que ver con el "estilo". Indudablemente asistimos a un ejercicio pastoral y magisterial de corte postmoderno. Las fronteras entre los diferentes niveles dogmáticos de este ministerio se hacen cada vez más borrosas por el uso sobreabundante de una comunicación directa, múltiple y personalizada. El papa privilegia, sin ninguna duda, una práctica de afinidades y de redes y deja en la sombra las lógicas institucionales tradicionales. Una nueva manera de hablar, de relacionarse está en forja.

Pero, sobre todo, asistimos a una extensión del discurso eclesial más allá de lo confesional. La Iglesia de Francisco no se ve a sí misma principalmente como testigo de su propio mensaje, ni siquiera como Madre y Maestra, sino como simple 
actriz en la masa humana, una "Iglesia pobre para los pobres". Privilegia más bien los aspectos no religiosos en la responsabilidad eclesial, y en su propio ministerio. Prioriza la misericordia universal y minimiza sistemáticamente los aspectos internos del discurso ${ }^{13}$.

Además, Francisco compromete la Iglesia entera a salir al encuentro y a ponerse del lado de la pluralidad cultural, religiosa, política en favor de una transformación del Mundo14.

\section{Cultura occidental, Tradición cristiana y futuro postreligional}

El paradigma postreligional, por ser uno de los Nuevos Paradigmas en Postmodernidad, surge en directo de la cultura occidental y de la occidentalización de la cultura global. Aunque Europa Occidental y América del Norte no sean ya los actores hegemónicos exclusivos en el escenario mundial (otras potencias, testigos de otros milenarios horizontes culturales, como la China o India, están amenazando apoderarse de la batuta imperial), sin embargo la globalizaciónOccidentalización del Mundo es hoy un proceso irreversible.

Con avances relativos y variantes según las regiones y las culturas, considero que el paradigma postreligional irá imponiéndose, de manera diferenciada y progresiva, a todo el planeta. Basta observar la urbanización vertiginosa de los continentes más pobres, el avance de la escolarización y el impacto de la comunicación virtual, para augurar esta evolución universal.

\footnotetext{
${ }^{13}$ Ver por ejemplo las consideraciones de Francisco sobre el celibato ministerial. Primero considera que no se trata de un dogma sino de una tradición de los últimos 900 años. En seguida afirma que no es una cuestión difícil ni tan importante y que la va a resolver en su tiempo (MAGISTER, 2014).

${ }^{14}$ Ver su exhortación apostólica "Gaudium Evangelii" y sus abundantes referencias al documento conclusiva de la conferencia de los obispos latinoamericanos en Aparecida en 2007.
} 


\subsection{Cristiandad, religión occidental}

Aunque muchos sectores de la laicidad occidental no lo quieran reconocer ${ }^{15}$, me parece difícil negar el aporte del Humanismo Cristiano a la configuración progresiva del Humanismo de Occidente.

Los principales valores, procesos y convicciones de la sociedad occidental han brotado de una dialéctica con el Cristianismo, que sea en oposición o en continuidad. Existe, por lo menos, una "familiaridad" de discursos, aún en la más rezas polémicas.

En su calidad de religión del Occidente, la Cristiandad, por otro lado, fue el primer sistema religioso (y uno de los pocos hasta hoy) en haber tenido que afrontar la crítica moderna e intentado responder, aún si esas respuestas fueron contradictorias y muchas veces inoportunas.

Propongo, por lo tanto, una primera hipótesis, basándome en dos presupuestos. El primero concierne el carácter de Humanismo del Cristianismo primitivo como discurso supra-religional, como lo hemos trabajado más arriba. La crisis del sistema religioso de Cristiandad invita a un retorno al Humanismo suprareligioso primitivo, como oportunidad única de un diálogo inédito y a la vez tradicional con el Mundo.

El segundo presupuesto acaba de ser expuesto brevemente: el sistema religioso de Cristiandad tiene una larga experiencia de confrontación con la crítica occidental, desde la filosofía griega hasta el ateísmo moderno, pasando por el Renacimiento y las diversas etapas de las ciencias. Por hipótesis, esta experiencia le permite abordar lo postreligional con una experiencia adelantada sobre los demás discursos religiosos de la Humanidad.

\footnotetext{
${ }^{15}$ Ver los debates alrededor de la frustrada Carta Magna europea.
} 
Como religión en crisis del Occidente, y por los dos motivos propuestos, emito la hipótesis de un rol específico del Cristianismo postmoderno en la configuración de un imaginario y de una simbólica postreligional.

\subsection{Crítica y autocrítica en la Tradición cristiana}

Desde sus orígenes en el martirio, el Cristianismo está confrontado ininterrumpidamente a la crítica externa, tanto religiosa como anti religiosa. Tiene una larguísima experiencia en la materia.

Pero, sobre todo, ha desarrollado desde el comienzo una valiosa experiencia de autocrítica. A pesar del carácter teocrático del sistema y de la permanente tentación autoritaria clerical, a la diferencia de casi todos los sistemas totalitarios modernos, la Cristiandad nunca pudo impedir la divergencia en su propio seno. Esta se expresó a la vez en el campo carismático (la vida monástica y religiosa, los santos) como intelectual y teológico.

No existe época, en la Historia de la Iglesia, sin debate contradictorio (con respuestas diversas y muchas veces contestables) con los que se llama los heréticos, los "infieles" o el mundo no creyente. En realidad este debate es siempre el motor dinámico del sensus fidelium. Lo más fecundo en su doctrina, hasta hoy, es fruto de estas confrontaciones, como lo hemos visto a propósito del Concilio, de la Teología de la Liberación y de las exploraciones teológicas más recientes.

Mi segunda hipótesis parte de esta constatación histórica: ċla capacidad de crítica y autocrítica no es acaso la mejor garantía de una evolución (dolorosa, no sin resistencia) hacia un Cristianismo postreligional? 


\subsection{Cristianismo, ética social y política}

Más que cualquier otro discurso religioso, el Cristianismo está habitado permanentemente por una dinámica de salida y de encuentro que llama evangelización o misión. Ninguna religión es más interesada en el Mundo y su devenir social, ético y político que el Cristianismo.

La crisis del sistema de Cristiandad cambia radicalmente este discurso. De triunfalista, conquistador y hegemónico, pasa, progresivamente, a lo que hoy Francisco llama la "propuesta” cristiana en una dinámica de encuentro y de mutua misericordia. Bendita crisis religiosa que nos hace abandonar la confrontación inquisitoria y conquistadora para la confraternización plural, pluri-religiosa, pluri cultural, dando prioridad a lo humano y al futuro del cosmos entero sobre las preocupaciones estrechamente confesionales y competitivas.

Mi tercera hipótesis se refiere, por lo tanto, a lo que Pablo VI llamó, en su discurso en la ONU, la experiencia de "experta en Humanidad” de la Iglesia. En el escenario postreligional, sueño con una Iglesia que pone esta experiencia al servicio de la Humanidad y de la Creación; una Iglesia sin otra ambición que colaborar, participar activamente, a la transformación mancomunada del Mundo, al advenimiento de una "Vida en Plenitud", para todos y todas, como dice san Juan.

\section{Conclusión: la era postreligional será mística, inter religiosa y supra religiosa}

Al comenzar estas reflexiones, constatábamos que el paradigma postreligional no implica el fin de las religiones, sino un giro hacia nuevas funciones en un paisaje cultural que ha dejado de ser agrario y mítico. En realidad, ¿cuál es el sentido concreto de este giro? Se presenta a la vez como un duelo y como un reto. 
El duelo es inmenso. Se trata de renunciar a toda función que tendría que ver con el desciframiento de la realidad global y con su manejo ideológico. La cultura científica agnóstica no necesita de pedagogo ni de juez. Ella misma se ha creado sus propias referencias y no necesita de ninguna "Mater et Magistra".

Son los discursos religiosos, más bien, los que, a la luz de las nuevas conciencias, necesitan una reformulación, una recreación de sus metáforas teológicas, cosmogónicas y antropológicas, como lo hemos visto. A pesar de signos contradictorios, en particular en los movimientos fanáticos y fundamentalistas de todas las religiones, el liderazgo social y político de las religiones llega a su fin con el paradigma postreligional. En una palabra, se trata de renunciar al poder directo sobre las sociedades y de optar por una presencia humilde de influencia y prestigio humanista.

Pero el reto lanzado por los Nuevos Paradigmas a las religiones no es menos importante. Debemos, urgentemente, encontrar, en el concierto movedizo y plural del Mundo postmoderno, un lugar específico nuevo. Esta nueva identidad, la veo a la vez de cara a los creyentes mismos y de cara al Mundo.

En adelante, los espacios teológicos, rituales y éticos de las religiones tendrán que brindar a los fieles, oportunidades de elaborar, juntos y juntas, simbólicas siempre nuevas de fe y de debatir constantemente con las nuevas cuestiones. Es lo que llamaría el "foro para un nuevo discipulado", una dinámica de "inteligencia de la fe". La prioridad tendrá que darse, en este foro, a la experiencia carismática y mística más que a la dogmática (cuya función interna tiene que replantearse también).

Las instituciones religiosas ya no estarán llamadas a preservar ni garantizar "la" Verdad, ni a difundirla a toda costa, sino a elaborar colectivamente un discurso creyente, que tenga en cuenta las interpelaciones actuales. Esta es la responsabilidad de cada confesión y de cada religión para con sus propios miembros. 
Pero existe, más que todo, un desafío supra-religioso e interreligioso de cara al Mundo. Más allá de las fronteras confesionales, ¿cómo las diferentes religiones pueden ofrecer mancomunadamente la riqueza de sus tradiciones éticas y espirituales, simbólicas e intelectuales, como contribución a lo que Francisco llama la transformación del Mundo, su plena Humanización?

El Humanismo como más allá de las religiones es lo que nos toca proponer juntos desde nuestras diversidades. Este reto interreligioso y suprareligioso implica una nueva comprensión del ecumenismo. No se tratará más de ponernos de acuerdo sobre nuestras creencias respectivas y nuestras doctrinas, aunque este nivel pueda tener su importancia en el primer nivel intra-confesional señalado más arriba.

¿En qué medida seremos capaces de presentar un Humanismo común y polifónico que surja de la experiencia de nuestra, igualmente común, experiencia de la trascendencia? Esta es la gran pregunta que sólo se podrá responder por un intenso diálogo de Humanismos creyentes y un proceso acelerado de sanación de nuestras taras seculares respectivas. Magnífica aventura, a contracorriente de la violencia religiosa endémica que nos aqueja.

Me permití, en estas páginas, emitir la hipótesis de una responsabilidad histórica específica del Cristianismo en dicha tarea. El Cristianismo podría ser el verdadero anfitrión de una invitación universal a este nuevo escenario religioso, sin afán hegemónico. Simplemente por las circunstancias históricas que hemos evocado en el párrafo anterior.

¿Estoy soñando algo imposible de cara a siglos de ostracismos mutuos y a los signos contradictorios del escenario religioso global de hoy? O, al contrario, ¿̇es precisamente por lo imposible que hay que apostar?, lo que el Papa Francisco parece querer intentar. 


\section{REFERENCIAS}

BIBLIA, La Santa. Disponible en:< http://www.wordproject.org/bibles/sp/ > Acceso en: 20 maio 2014.

BOFF, Leonardo. Iglesia: carisma y poder. Ensayos de eclesiología militante. Santander: Sal Terrae, 2002.

CARTA A DIOGNETO. Los cristianos em el mundo. Disponible en: <http://www.vatican.va/spirit/documents/spirit_20010522_diogneto_sp.html>.Acceso en: 20 maio 2014.

EHRMAN, Bart D. How Jesus became God: The exalation of a Jewish Preacher from Galilee. New York: HarperOne, 2014.

EVANGELII GAUDIUM: Exortação Apostólica sobre o anúncio do Evangelho no mundo atual. nov. 2013. Disponible en:

<http://mobile.vatican.va/content/francesco/pt/apost_exhortations/index.html>.Acceso en: 20 maio 2014.

JOHNSON, Elizabeth A. Ask the beasts: Darwin and the God of Love. London: Bloomsbury Academic, 2014.

JUAN PABLO II. Mensaje a los miembros de la Academia Pontifícia de Ciências. Vaticano, out. 1996. Disponible en:

<http://www.vatican.va/holy_father/john_paul_ii/messages/pont_messages/1996/docu ments/hf_jp-ii_mes_19961022_evoluzione_sp.html>. Acceso en: 20 maio 2014.

KEARNEY, Richard. Anatheism: returning to God after God. New York: Columbia University Press, 2010.

LOYSY, Alfred. Les évangiles Synoptiques. Paris: Ceffonds, 1907.

MAGISTER, Sandro. Francisco habla, Scalfari transcribe, Brandmüller suspende. Disponible en: <http://chiesa.espresso.repubblica.it/articolo/1350847?sp=y>. Acceso en: 19 jul 2014. 